\title{
Assessment of Portunus (Portunus) trituberculatus (Miers, 1876) stock in the northern East China Sea
}

\author{
YINGBIN WANG, LI GAO AND YUNXIA CHEN* \\ School of Fisheries, Zhejiang Ocean University, Zhoushan - 316 022, China \\ "Marine Fisheries Bureau of Putuo District, Zhoushan - 316 100, China \\ e-mail:yingbinwang@126.com
}

\begin{abstract}
Portunus (Portunus) trituberculatus (Miers, 1876) is one of the important commercial crustaceans in the northern East China Sea. Although extensive research on aquaculture of the species is being carried out, the wild stock is scientifically unassessed. In this paper, the total catch of P. trituberculatus in the northern East China Sea during 2001 and 2015 were classified into 4 carapace width (CW) groups ( $<60 \mathrm{~mm}, 60-110 \mathrm{~mm}, 110-150 \mathrm{~mm}$ and $>150 \mathrm{~mm}$ ), for estimation of the maximum sustainable yield (MSY) and the spawner-recruitment relationships for wild stock and released stock were built, respectively. Standing biomass, spawning biomass and catch were predicted under the assumptions that fishing intensity and quantity of $P$. trituberculatus released were kept at the levels of those in 2015. The results showed that the MSY of P. trituberculatus is about $14.2 \times 10^{4} \mathrm{t}$ and the corresponding fishing effort $\left(\mathrm{E}_{\mathrm{MSY}}\right)$ is about $14.8 \times 10^{4}$ tonnage (both the crab pot vessels and trawl vessels were standardised to gillnet vessels). In future, if fishing effort level and the release number equals to those in 2015 , the biomass, spawning biomass and catch of $P$. trituberculatus would remain at $58.9 \times 10^{4} \mathrm{t}, 53.1 \times 10^{4}$ $\mathrm{t}$ and $15.6 \times 10^{4} \mathrm{t}$, respectively. The present stock assessment study was conducted with limited data and further survey data in future may provide more accurate stock assessment to evolve management strategies.
\end{abstract}

Keywords: Carapace width group, Northern East China Sea, Portunus trituberculatus, Stock assessment

\section{Introduction}

Portunus (Portunus) trituberculatus (Miers, 1876) is the world's largest crab fishery, accounting for about one quarter of the crabs caught commercially worldwide (Liu et al., 2013) and it is also one of the most important economic species in China especially in the East China Sea. It is reported that the catch of $P$. trituberculatus in the East China Sea accounts for about $50 \%$ in the three main fishing areas: the East China Sea, the Yellow Sea and the Bohai Sea (Song et al., 2003; Yu et al., 2004; Liu et al., 2013). The northern East China Sea is the largest production area for P. trituberculatus in the East China Sea, accounting for more than $40 \%$ of the catch in the East China Sea (Song et al., 2003; Yu et al., 2003).

Before 2001, the catch of $P$. (P.) trituberculatus in the Northern East China Sea varied between $5 \times 10^{4} \mathrm{t}$ and $10 \times 10^{4}$ t. In 2001, P. trituberculatus was for the first time added into the list of species for stock enhancement in the northern East China Sea (Wang et al., 2009b). Since then, the catch of $P$. trituberculatus varied between $7 \times 10^{4} \mathrm{t}$ and $10 \times 10^{4} \mathrm{t}$. But after 2010, the numbers released and subsequent enhancement significantly increased. In 2011 more than 20 million juveniles were released, with increase in number in subsequent years and in 2014, it exceeded 95 million. Thus, the catch of
P. (P.) trituberculatus also increased substantially from about $8 \times 10^{4} \mathrm{t}$ to more than $20 \times 10^{4} \mathrm{t}$ within 5 years.

Influence of factors like fishing pressure and environmental changes resulted in variation in P. (P.) trituberculatus catch (Wang et al., 2017b). $P$. (P.) trituberculatus is one of the target species for commercial fishing in the northern East China Sea (Yu et al., 2004). In recent years, the promising trend of increasing catch has been a topic of research and the increase was attributed to stock enhancement programs, rise of sea temperature or changes in the trophic interactions (Wang et al., 2017a; b). Earlier studies on $P$. (P.) trituberculatus mainly focused on biology (Wu et al., 2016; Yuan et al., 2016), disease (Xu et al., 2007), breeding (Wang et al., 2014a), aquaculture techniques (Wang et al., 2009a) and nutrition (Han et al., 2013). In the present study, MSY of $P$. (P.) trituberculatus, their spawner-recruit relationships and prediction of possible variations of biomass and catch in the northern East China Sea were estimated using catch-at-length analysis.

\section{Materials and methods}

Data

The vessels operating drift gillnet, crab pot and trawlcatch more than $90 \%$ of $P$. (P.) trituberculatus in the 
northern East China Sea were selected as sample vessels. The rest $10 \%$ are usually bycatch from other fishing gears. Random collections of $P$. (P.) trituberculatus samples were carried out monthly from the 3 types of sample vessels during May 2015 and May 2016. The fishing area of the selected vessels were the northern East China Sea (Fig. 1). Totally, 769 samples were collected. Major biological indices including carapace width $(\mathrm{CW}, \mathrm{mm})$, carapace length $(\mathrm{CL}, \mathrm{mm})$ and body weight $(\mathrm{W}, \mathrm{g})$ were recorded and the $\mathrm{CW}$ frequency matrix was built. The individuals with CW's shorter than $60 \mathrm{~mm}$ were treated as immature (Wang et al., 2017a), which is specified in the Zhejiang local standard: "Allowable size of capture and juvenile proportion of key marine fishery resources" (DB33/T949, 2014). Therefore, in the current study the individuals with CW's shorter than $60 \mathrm{~mm}$ were treated as recruit population.

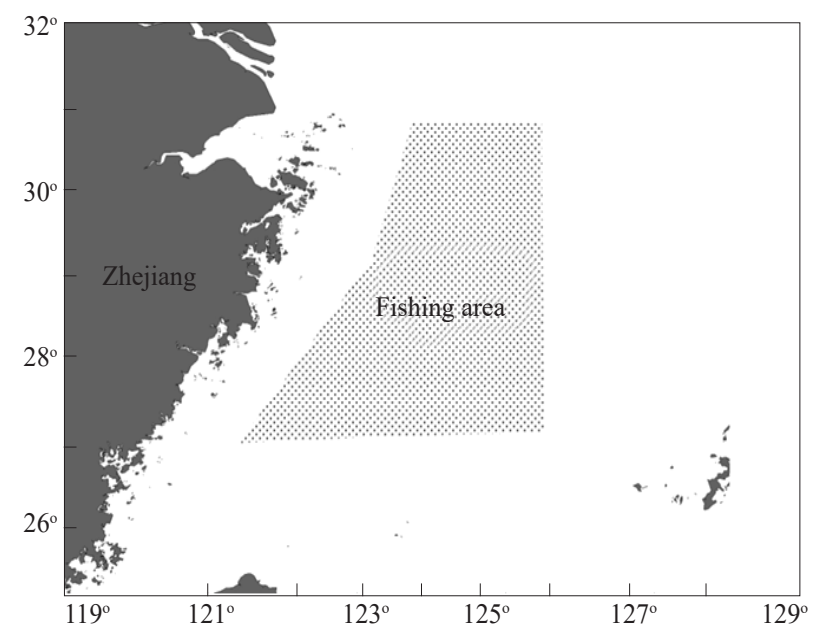

Fig. 1. Sampling area of $P$. (P.) trituberculatus in the northern East China Sea

The catch and fishing effort of the three major fishing gears viz., crab pot, drift gillnet and bottom otter trawl, were selected for the study. Drift gillnet data was used for standardising the fishing gears. The standardisation was done in tonnage and the data on released juveniles and population enhancement were obtained from the Administrative Department for Fisheries. Every year, from April to June, the fishery Bureaus of the coastal cities and counties of the northern East China Sea organise juvenile crab releasing for stock enhancement. For catch and effort analysis, data collected during 2001 and 2015, obtained from the China Fisheries Statistics Yearbooks, were used (Fig. 2), whereas for the juvenile release and enhancement data, the number of juvenile crab released during 2011 and 2015, obtained from fisheries management departments, were taken into consideration (Wang et al., 2017b).

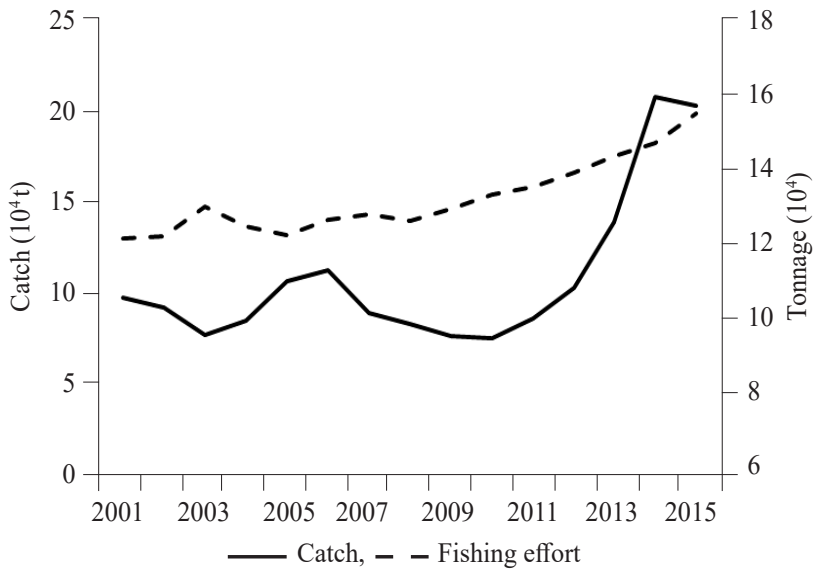

Fig. 2. Annual catch and fishing effort of $P$. (P.) trituberculatus from 2001 to 2015 in the northern East China Sea

Commercial CPUE (catch per unit effort) can vary owing to many factors other than the abundance of the population. Therefore, the CPUE need to be standardised to eliminate the effects of these factors (Hilborn and Walters, 1992). In the current study, the CPUE was standardised using GLM (Generalized Linear Model) to remove the effects on time, vessels and average seawater temperature (Goodyear and Bigelow, 2012; Wang et al., 2014a). Usually the index is assumed to be related to abundance by a constant of proportionality, the catchability coefficient. A population-dynamics model is then fitted to the abundance index by minimising the difference between the abundance index and the model-predicted biomass scaled by the catchability coefficient (Maunder, 2001). Fig. 3 depicts the nominal CPUE and standardised CPUE of P. (P.) trituberculatus from 2001 to 2015.

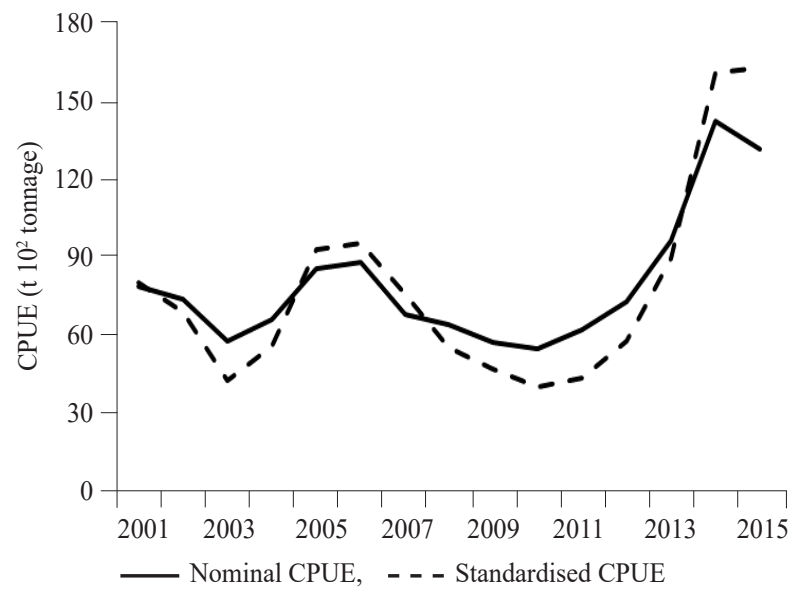

Fig. 3. The nominal CPUE and standardised CPUE of P. (P.) trituberculatus from 2001 to 2015 in the northern East China Sea 


\section{Methods}

The MSY of $P$. (P.) trituberculatus in the northern East China Sea was estimated using Schaefer model with observation error:

$$
\begin{aligned}
& 1_{a}=\frac{C_{a}}{E_{a}} \\
& 1_{a}=q B+\varepsilon_{a} \\
& B_{a+1}=B_{a}+B_{a} r\left[1-\frac{B_{a}}{B_{0}}\right]-C_{a}
\end{aligned}
$$

where $I_{a}$ is the CPUE in year $a, C$ is catch, $E$ is fishing effort and $B$ is biomass, $\varepsilon$ is the error, which follows a normal distribution, $N\left(0, \sigma_{1}^{2}\right) . q$ represents catchability, $r$ is population intrinsic growth rate and both of these were assumed constant (Wang et al., 2014b). The likelihood function is :

$$
L(1 \mid \theta)=\Pi_{a} \frac{1}{\sigma_{1} \sqrt{2 \pi}} \exp \left[-\frac{\left[1_{a}-\left(q B_{a}\right)\right]^{2}}{2 \sigma_{1}^{2}}\right]
$$

The age of $P$. (P.) trituberculatus is difficult to determine, thus CW-based data were used for the spawnerrecruit (S-R) analysis and prediction of biomass and catch. The total catches were classified into $4 \mathrm{CW}$ groups ( $<60 \mathrm{~mm}, 60 \sim 110 \mathrm{~mm}, 110 \sim 150 \mathrm{~mm}$ and $>150 \mathrm{~mm}$ ) based on the CW proportions of the 4 groups in the samples (Wang et al., 2017a).

Ricker model was built to describe the spawnerrecruit relationship:

$$
\mathrm{R}=\alpha \mathrm{Se}^{-}-\beta \mathrm{S}_{\mathrm{e}} \varepsilon
$$

where $R$ is recruitment and $S$ is spawner and recruitment was assumed 1 year lagged; $\alpha$ and $\beta$ are two parameters; $\varepsilon$ the error, which follows a normal distribution, $N\left(0, \sigma_{2}^{2}\right)$. Maximum likelihood method was used to estimate the two parameters and the target equation is:

$$
\mathrm{L}(\mathrm{R} \mid \theta)=\Pi_{\mathrm{a}} \frac{1}{\mathrm{R}_{\mathrm{a}} \sigma_{1} \sqrt{2 \pi}} \exp \left[-\frac{\left[\ln \mathrm{R}_{\mathrm{a}}-\ln \hat{\mathrm{R}}_{\mathrm{a}}\right]^{2}}{2 \sigma_{2}^{2}}\right]
$$

where Ra represents the estimated recruitment in year $a$.

As the large number of released juveniles may impact the spawner-recruit relationship, we built different spawner-recruit relationships before and after 2010 for wild stock and multi-stock (both wild and released stocks) respectively. Before 2010, the released quantity was less (about 2 million per year), but after that, the quantity released dramatically increased (more than 90 million in 2014), which might have distorted the original spawnerrecruit relationship of the wild stock (Wang et al., 2017a ). After 2010, the spawner-recruit relationship comprised 2 parts, i.e. spawner-recruit relationships for wild stock and for released stock. We assumed that after 2010, the feature of spawner-recruit relationship for wild stock is the same as that before 2010 .

A catch-at-width model was used to predict the biomass, spawner abundance and catch in the future:

$$
\begin{aligned}
& \mathrm{N}_{\mathrm{L}+\Delta \mathrm{L}, \mathrm{a}+\Delta \mathrm{a}}=\mathrm{N}_{\mathrm{L}, \mathrm{a}} \mathrm{e}^{-\mathrm{Z}} \mathrm{L,a} \\
& \mathrm{C}_{\mathrm{L}, \mathrm{a}}=\frac{\mathrm{FL}, \mathrm{a}}{\mathrm{F}_{\mathrm{L}, \mathrm{a}}+\mathrm{M}_{\mathrm{L}}} \mathrm{N}_{\mathrm{L}, \mathrm{a}}\left(1-\mathrm{e}^{\left.-\mathrm{Z}_{\mathrm{L}, \mathrm{a}}\right)}\right. \\
& \mathrm{F}_{\mathrm{L}, \mathrm{a}}=\mathrm{F}_{\mathrm{a}} \mathrm{S}_{\mathrm{L}} \\
& \mathrm{S}_{\mathrm{L}}=\frac{1}{1+\mathrm{e}^{-\mathrm{S}_{1}\left(\mathrm{~L}-\mathrm{S}_{2}\right)}}
\end{aligned}
$$

where $\mathrm{N}_{\mathrm{L}, \mathrm{a}}$ represents abundance of $P$. (P.) trituberculatus for $\mathrm{CW}$ group $L$ in year $a . \mathrm{C}_{\mathrm{L} \text {, a }}$ is catch for $\mathrm{CW}$ group $L$ in year $a . \Delta L$ is the increase of $\mathrm{CW}$ and $\Delta a$ is the corresponding time when $\mathrm{CW}$ increase, $\Delta L . M_{L}$ represents the coefficient of natural mortality for width $L$ ( $L$ was separated into 2 groups for mortality estimation, i.e. $L \geq 60$ and $L<60 \mathrm{~mm}$ ), which was assumed constant through years. $M_{L}$ for $L \geq 60 \mathrm{~mm}$ was estimated using the Beverton and Holt (1957) method:

$$
\mathrm{M}=\frac{\mathrm{L}_{\infty}-\overline{\mathrm{L}}}{\mathrm{L}-\overline{\mathrm{L}}_{\mathrm{c}}}
$$

where $\mathrm{L}_{\infty}$ is the asymptotic $\mathrm{CW}, \overline{\mathrm{L}}$ is the average $\mathrm{CW}$ and $\mathrm{L}_{c}$ is the minimum $\mathrm{CW}$ in the catch. $\mathrm{L}_{\infty}$ was estimated based on the $\mathrm{CW}$ frequency data using the software FiSAT II (Wang et al., 2018). Based on above Eq. (6), the $M_{L}$ for $L \geq 60 \mathrm{~mm}$ was estimated as $0.56 \mathrm{yr}^{-1}$.

The individuals with $L<60 \mathrm{~mm}$ are immature, and the $M_{L}$ is usually higher than those with $L \geq 60 \mathrm{~mm}$. Ariyama and Secor (2010) reported that $M$ for $L<60 \mathrm{~mm}$ equals to $1.1 \mathrm{yr}^{-1}$. Input on this aspect was also derived based on consultation with fishermen, aquaculturist and researchers, who indicated that $M$ decreases exponentially from stage I juvenile crab to pre-sexually mature crab. Therefore, we built the abundance equation based on the data from aquaculture farm of $P$. (P.) trituberculatus as: $\mathrm{N}_{\mathrm{L}+\Delta \mathrm{L}}=\mathrm{N}_{\mathrm{L}} \mathrm{e}^{-} \mathrm{M}_{\mathrm{L}<60}$ and reduced the proportion of intra-specific competition, given the higher density in aquaculture systems than that in the natural seawater. Thus the estimated $M_{L<60}$ is about $1.5 \mathrm{yr}^{-1}$. The average of the estimated $M$ and the 
reference $M$, i.e. $1.3 \mathrm{yr}^{-1}$, as the value of $M_{L<60}$ was used in our study.

$Z_{L, a}$ represents the coefficient of total mortality of width $L$ in year $a$, which equals to the sum of $M$ and fishing mortality $(F)$ :

$$
\mathrm{Z}_{\mathrm{L}, \mathrm{a}}=\mathrm{M}_{\mathrm{L}}+\mathrm{F}_{\mathrm{L}, \mathrm{a}}
$$

$Z$ in year 2015 was estimated using the length converted catch curve analysis method based on carapace width data of current year (Pauly, 1983). Therefore, $F$ ( $F_{L a}$ represents the coefficient of fishing mortality of width $L$ in year $a$ ) in 2015 can be calculated using Eq. (7), which equals to $0.66 \mathrm{yr}^{-1}$, and the $F$ 's from 2001 to 2004 were estimated proportionally according to the fishing effort within these years. $S_{L}$ is selectivity, which follows logistic function with two parameters $S_{1}$ and $S_{2}$ equal to 2.10 and 11.78, respectively. The values of parameters were determined according to historical data and widthratios in the samples. Thus, $Z$ from 2001 to 2014 could also be obtained using Eq. (7).

\section{Results}

\section{Carapace width and body weight compositions}

Based on the samples, catch data and abundance exponential function, we calculated the percentages of abundance and biomass for the $P$. $(P)$ trituberculatus population (Fig. 4 and 5). The group with $\mathrm{CW}$ shorter than $60 \mathrm{~mm}$ takes the absolute dominance for the abundance percentage (Fig. 4) and CW between 110 and $150 \mathrm{~mm}$ dominate the biomass percentage (Fig. 5). After 2011, the proportions for shorter CWs gradually increased, which may be due to the large number of released juveniles.

\section{Surplus production}

The estimated production curve is shown in Fig. 6. The estimated MSY is about $14.2 \times 10^{4} \mathrm{t}$ $\left(\mathrm{SE}=30.68714 .2 \times 10^{2} \mathrm{t}\right)$ and the corresponding $E_{\mathrm{MSY}}$ is

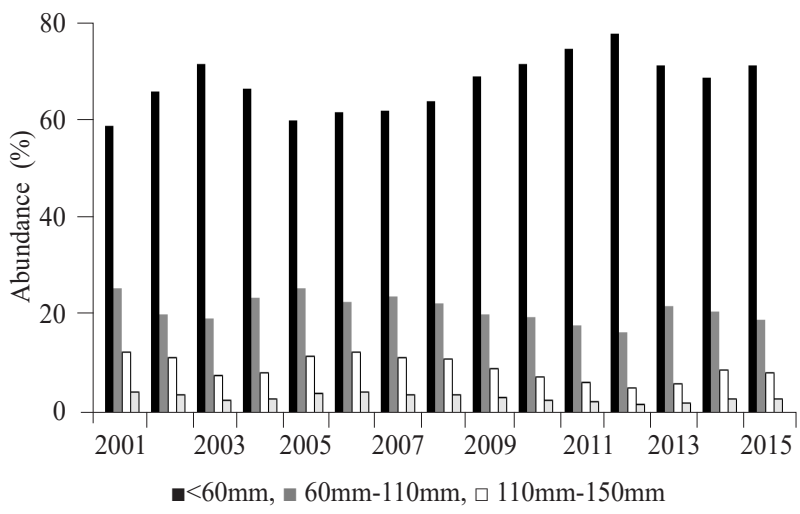

Fig. 4. Calculated percentage of abundance of $P$. (P.) trituberculatus for different $\mathrm{CW}$ groups in the northern East China Sea

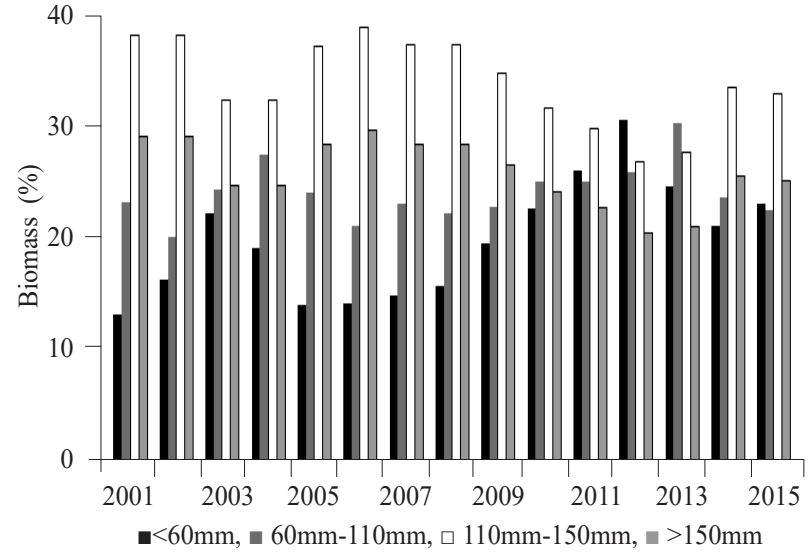

Fig. 5. Calculated percentage of biomass of $P$. (P.) trituberculatus for different carapace width groups in the northern East China Sea

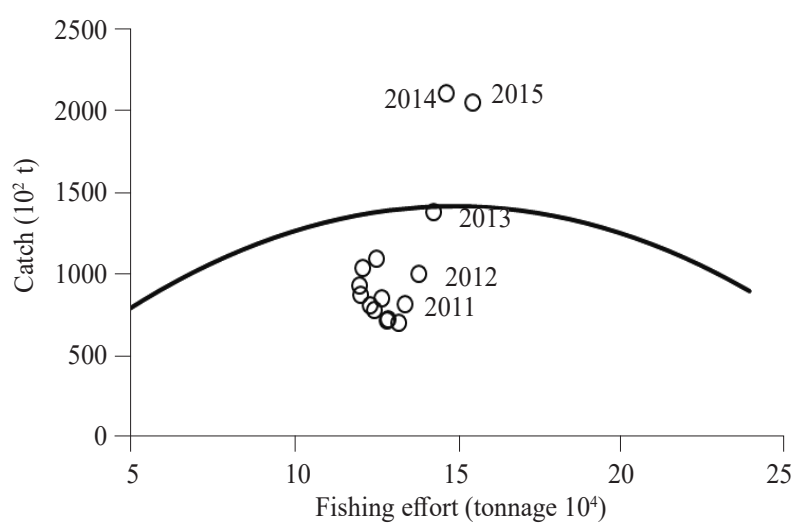

Fig. 6. Surplus production curve of P.(P.) trituberculatus in the northern East China Sea

about $14.8 \times 10^{4}$ tonnage. Other Schaefer parameters including $r$, initial biomass $\left(\mathrm{B}_{0}\right)$ and $q$ are 0.151 , $37706.40 \times 10^{2} \mathrm{t}$ and 0.00505 respectively. The mean relative estimation error (REE) is about $3.32 \times 10^{4} \mathrm{t}$, which indicated that the differences between observed and predicted catches are acceptable. From Fig. 6 we can see that the fishing effort fluctuated around the $E_{\mathrm{MSY}}$ from 2001 to 2010 , but began to increase since 2011.

\section{Spawner-recruit relationship of wild stock}

The spawner-recruit relationship for wild stock was built using the data from 2001 to 2010 (Fig. 7). From Fig. 6 we can see that the spawner-recruit relationship of wild stock is density-dependent and the spawner abundance varied between about 3 and 5 billion, while the recruitment varied between 5 and 8 billion.

\section{Spawner-recruit relationship of released stock}

The spawner-recruit relationship for released stock was built using the data from 2011 to 2015 (Fig. 8). During 


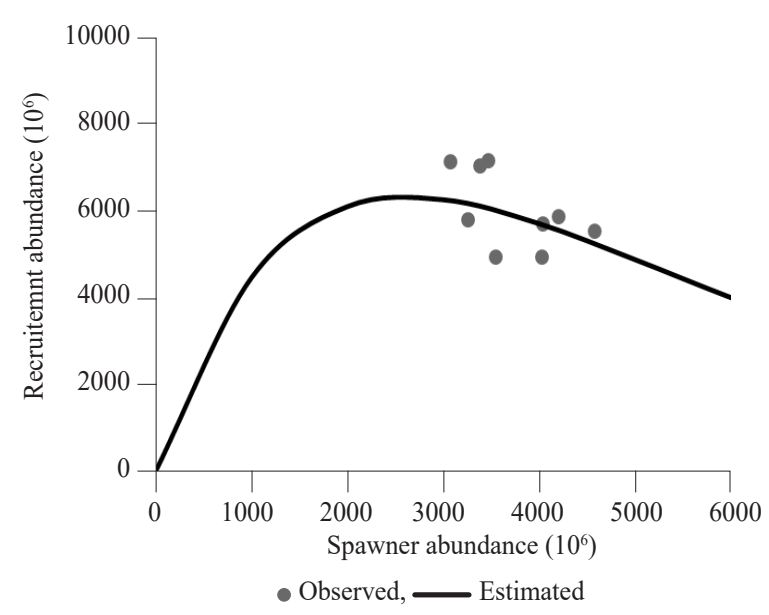

Fig. 7. Spawner-recruit relationship of wild $P$. (P.) trituberculatus in the northern East China Sea

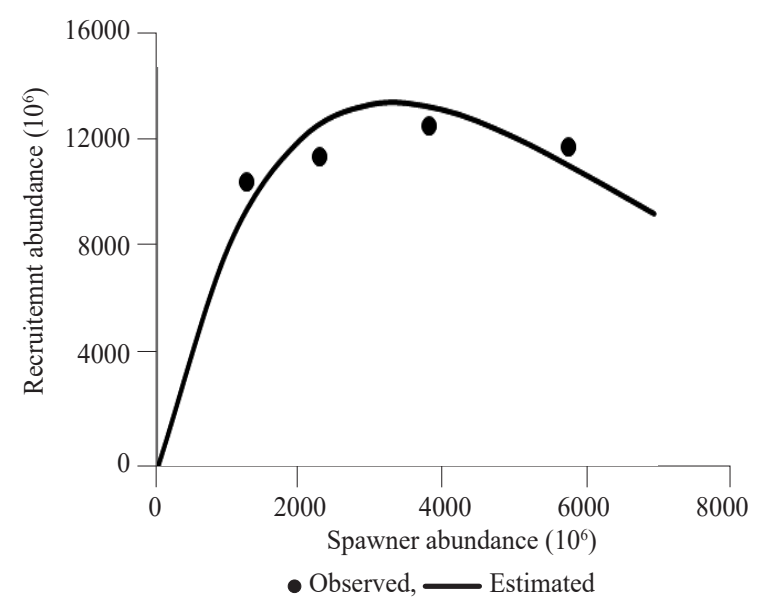

Fig. 8. Spawner-recruit relationship of released stock of $P$. (P.) trituberculatus in the northern East China Sea

these years, the numbers released continuously increased and the recruitment abundance varied between 11 and 14 billion. The reproductive rate (R/P) of released stock was higher than that of wild stock.

\section{Prediction of population dynamics}

The biomass, spawning biomass and catch of $P$. (P.) trituberculatus in the northern East China Sea were predicted under the assumption that fishing intensity and released number were stable at current levels. From Fig. 9 it can be observed that the standing biomass, spawning biomass and catch increased rapidly from 2013 to 2015 , which conform to fishery data collected during the period. This increase may be attributed to the large number of juvenile crabs released during these years. If the released number is kept at about 3 million per year as in 2015, in future, the biomass, spawning biomass and catch will accordingly decrease and reach stable levels

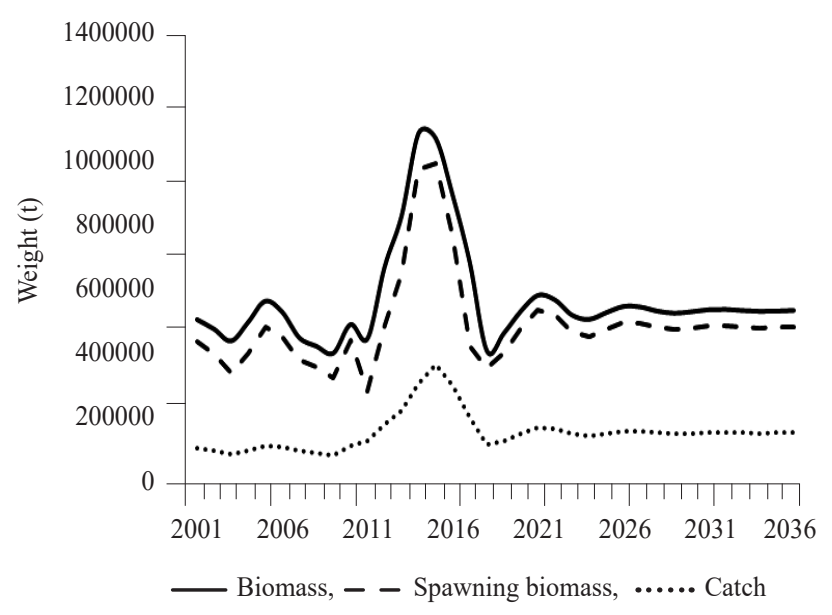

Fig.9. Predicted biomass, spawning biomass and catch of P. (P.) trituberculatus in the northern East China Sea when fishing intensity and released number were kept at current level

$\left(58.9 \times 10^{4} \mathrm{t}, 53.1 \times 10^{4} \mathrm{t}\right.$ and $15.6 \times 10^{4} \mathrm{t}$, respectively for the 3 variables) within the next 10 years.

\section{Discussion}

P. (P.) trituberculatus is the world's largest crab fishery, accounting for about one quarter of the crabs caught commercially worldwide (Liu et al., 2013) and it is also one of the most important fisheries in China. The fishery of $P$. (P.) trituberculatus was initiated in China in the 1960 's and when the drift gillnet and crab pot were popularised, the catch increased substantially in 1980's and 1990's. Before 2011, the catch of $P$. (P.) trituberculatus showed a negative correlation with fishing effort (FAO, 2016).

Stock enhancement is one of the oldest, yet most controversial and least well-understood approaches to fisheries management (Lorenzen, 2005). Stocking of hatchery produced fish has been practiced on a large scale since the mid-nineteenth century and systematic transfers of wild juveniles probably have a much longer history (Lorenzen et al., 2001; Lorenzen, 2005). Additive effects of stock enhancement have been documented in several situations (Leber et al., 1995; Brennan et al., 2008). Fig. 9 indicates that the large quantity of released $P$. (P.) trituberculatus can impact its biomass and spawner abundance (Wang et al., 2017a, b). The stock composed by released individuals may have different feature from that of wild stock and may also affect the dynamics of the wild stock. It can be presumed that the stock enhancement of $P$. (P.) trituberculatus in the northern East China Sea lacked scientific support, since the enhancement capacity of the program was not scientifically estimated. In the beginning, the juveniles released for enhancement were 
less in number, but after 2010 the number dramatically increased. In 2011, more than 20 million juveniles were released and the number continuously increased and in 2014, it exceeded 95 million. With increase in released juveniles, catch increased, which reduced the income of fishermen since supply exceeded demand. Thus, in 2015 the government cut down about $97 \%$ of the juveniles being released compared to that of 2014, to change the situation of high output and low income. The drastic reduction in the number of juveniles being released within a short period is not sensible since the effect on its population and the subsequent ecological consequences are not clear. It was reported that the stock enhancement of $P$. (P.) trituberculatus has already changed the original spawner-recruit relationships (Wang et al., 2017a). Although these are not the final conclusions that are approved by other researchers, we recommend that comprehensive stock assessment of $P$. (P.) trituberculatus should be carried out and the effect of stock enhancement should be considered at the same time. It should be noted that the identification of the individual whether they are from wild or released stock is difficult and traditional techniques, such as morphology or tagging are not useful for this purpose. Thus, the separation of wild stock from released stock is the source of error in this type of analysis, which may get reduced by relying on genetic techniques in future studies.

The estimated MSY from Schaefer surplus production is about $14.2 \times 10^{4} \mathrm{t}$ and $E_{\mathrm{MSY}}$ is about $14.8 \times 10^{4}$ tonnage for vessels catching $P$. (P.) trituberculatus both as target species and bycatch species. From Fig. 6 it can be observed that current catch of $P$. (P.) trituberculatus in the study area exceed the MSY level and the fishing effort is beyond the $E_{\mathrm{MSY}}$ as well. Compared with historical records, the fishing efforts during 2012 and 2014 were similar with $E_{\mathrm{MSY}}$. However, the catches during those years fluctuated between $9.9 \times 10^{4} \mathrm{t}$ and $21.0 \times 10^{4} \mathrm{t}$. This may be the result of stock enhancement which brought additional biomass into the study area. Therefore, the MSY is a combined result of wild and released stock.

Spawner-recruit relationship is one of the most important and generally most difficult problems in biological assessment of fisheries (Hilborn and Walters, 1992). It is important not only because the relationship describes the ability of a stock to maintain abundance in response to intensive fishing pressure, but also because it provides a basis for predicting the range of recruitment that is expected for a given size of spawning stock (Jennings et al., 2001). The results indicated that release of juveniles may have potential effects on the natural recruitment of $P$. (P.) trituberculatus. A spawner-recruit model was built with data on both wild and released stock combined, but it was inconsistent with the traditional spawner-recruit forms (Wang et al., 2017a), which showed that large amount of released P. (P.) trituberculatus during 2011 and 2014 might have impacted the wild stock structure. The catch of $P$. (P.) trituberculatus in the East China Sea continuously increased during the past 5 years, which led to many hypotheses (Wang et al., 2017b). Increase in temperature and decrease in abundance of demersal fishes which are the predators of crabs could also be potential factors that may impact recruitment. Fig. 9 was obtained under the assumption that the number of juveniles that may be released in the future is equal to that in 2015 . The rapid increase in biomass, spawning biomass and catch during 2013 and 2015 is attributed to the large number of juveniles released. If the released number is reduced to a relatively low level in the next few years, biomass, spawning biomass and catch would also decrease. Simulation analyses showed that, when the released number of juveniles are kept between 0 and 80 million in the future, the biomass, spawning biomass and catch varied within $49 \times 10^{4} \mathrm{t}$ and $92 \times 10^{4} \mathrm{t}, 44 \times 10^{4} \mathrm{t}$ and $83 \times 10^{4} \mathrm{t}$ and $13 \times 10^{4} \mathrm{t}$ and $24 \times 10^{4} \mathrm{t}$ respectively (Pers. Comm.).

This forms the first study on stock assessment of $P$. (P.) trituberculatus in the northern East China Sea. Fishing effort during 2001 and 2015 were relatively concentrated, which might have affected the estimate of MSY. Stock enhancement can affect the spawner-recruit relationship and the predictions of biomass and catch. The value of $M$ (especially $M$ for $\mathrm{CW}<60 \mathrm{~mm}$ ) was based on inputs from fishermen, aquaculturist as well as researchers, which may be also one of the error source in our assessment. Therefore, in future studies, there is need to separate the recruit process into different stages and conduct experiments on fecundity to reveal the interaction between wild and released stock. Sensitivity analyses need to be carried out to evaluate the impact of the values of $M$ on the assessment results. Additionally, more historical data must be used in the stock assessment of $P$. (P.) trituberculatus for more accurate results.

\section{Acknowledgements}

This research was supported by the National Key Research and Development Program of China under contract No. 2017YFA0604902; the Science and Technology Project of Zhoushan under contract No. 2017C43013 and the Public Welfare Technology Application Research Project of Zhejiang under contract No. 2015 C33094.

\section{References}

Ariyama, H. and Secor, D. H. 2010. Effect of environmental factors, especially hypoxia and typhoons on recruitment of the gazami crab Portunus trituberculatus in Osaka Bay, 
Japan. Fish. Sci.,76: 315-324. DOI: 10.1007/s12562-0090198-6.

Beverton, R. J. H. and Holt, S. J. 1957. On the dynamics of exploited fish populations. Fishery Investigations Series 2, Marine fisheries, Great Britain Ministry of Agriculture. Fisheries and Food, UK, 19: 533 pp.

Brennan, N. P., Walters, C. J. and Leber, K. M. 2008. Manipulations of stocking magnitude: addressing densitydependence in a juvenile cohort of common snook (Centropomus undecimalis). Rev. Fish. Sci., 16(1-3): 215-227. doi.org/10.1080/10641260701689022.

DB33/T949 2014. Allowable size of capture and juvenile proportion of key marine fishery resources. Zhejiang Province Administration of Quality and Technology Supervision, Zhejiang, China, 14 pp.

FAO 2016. FishStat J-software for fishery statistical time series. Statistics and Information Branch (FIPS), Food and Agricultural Organisation, Rome, Italy.

Goodyear, C. and Bigelow, K. 2012. Preliminary analyses of simulated longline Atlantic blue marlin CPUE with HBS and generalised linear models. Coll. vol. Sci. Pap. ICCAT. 68., p. 1510-1523.

Han, T., Wang, J. T., Hu, S. X., Li, X. Y., Li, R. H., Mu, C. K. and Wang, C. L. 2013. Needs of dietary cholesterol for juvenile swimming crab Portunus trituberculatus. Oceanologia et Limnologia Sinica, 44(6): 1524-1529.

Hilborn, R. and Walters, C. J. 1992. Quantitative fisheries stock assessment: choice, dynamics and uncertainty. Chapman and Hall, New York, p. 241-296.

Jennings, S., Kaiser, M. J. and Reynolds, J. D. 2001. Marine fisheries ecology. Blackwell Science Ltd., Malden, UK, p. $70-89$.

Leber, K. M., Brennan, N. P. and Arce, S. M. 1995. Marine enhancement with striped mullet: are hatchery releases replenishing or displacing wild stocks? Proceedings of the American Fishery Society Symposia, 15: 376-387.

Liu, S. S., Jin, S. and Hurtado, L. A. 2013. Genetic differentiation of Portunus trituberculatus, the world's largest crab fishery, among its three main fishing areas. Fish. Res., 148: 38-46. DOI: 10.1016/j.fishres.2013.08.003.

Lorenzen, K. 2005. Population dynamics and potential of fisheries stock enhancement: practical theory for assessment and policy analysis. Philos. Trans. R. Soc. Biol. Sci., (1453): 171-189. doi.org/10.1098/rstb.2004.1570.

Lorenzen, K., Amarasinghe, U. S., Bartley, D. M., Bell, J. D., Bilio, M., de Silva, S. S., Garaway, C. J., Hartmann, W. D., Kapetsky, J. M., Laleye, P., Moreau, J., Sugunan, V. V. and Swar, D. B. 2001. Strategic review of enhancements and culture-based fisheries. In: Subasinghe, R. P., Bueno, P., Phillips, M. J., Hugh, C. and McGladdery, S. E. (Eds.), Aquaculture in the third millennium, Food Agricultural Organisation, Rome, Italy, p. 221-237.
Maunder, M. N. 2001. A general framework for integrating the standardisation of catch per unit of effort into stock assessment models. Canadian J. Fish. Aquat. Sci., 58(4): 795-803. doi.org/10.1139/f01-029.

Pauly, D. 1983. Some simple methods for the assessment of tropical fish stock. FAO Fish. Tech. Pap., 234: 52.

Song, H. T., Yu, C. G. and Xue, L. J. 2003. The East China Sea economic crustacean fisheries biology. China Ocean Press, Beijing, China, 228 pp.

Wang, X. Q., Cao, M., Yan, B. L. and Zhang, Q. Q. 2009a. Integrated culture of swimming crab Portunus trituberculatus. Fish. Sci., 28(2): 105-108.

Wang, W. D., Yu, G. P., Liang, J., Zhang, D. B., Xu, H. X. and Yu, C. B. 2009b. Selection and application of suitable stock enhancement and releasing species in the East China Sea. J. Zhejiang Ocean Univ. (Natural Science), 28(4): 379-383.

Wang, H. F., Gao, B. Q., Duan, Y. F., Han, X. L., Liu, P. and Li, J. 2014a. Comparison of reproduction and early growth of offspring between hybrid and inbred families in swimming crab Portunus trituberculatus. J. Dalian Ocean Univ., 29(2): 114-120.

Wang, Y. B., Zheng, J. and Yu, C. G. 2014b. Stock assessment of chub mackerel (Scomber japonicus) in the central East China Sea based on length data. J. Mar. Biol. Assoc. U. K., 94(1): 211-217. doi.org/10.1017/S0025315413001434.

Wang, Y. B., Wang X. G., Ye, T., Chen, L. M. and Zhou, C. Y. 2017a. Spawner-recruit analysis of Portunus trituberculatus in the case of stock enhancement implementation: a case study in Zhejiang Sea area, China. Turkish J. Fish. Aquatic Sci., 17(2): 293-299.

Wang, Y. B., Ye, T., Wang, X. G. and Zhou, C. Y. 2017b. Impact of main factors on the catch of Portunus trituberculatus in the Northern East China Sea. Pakistan J. Zool., 49(1): 15-19. DOI: http://dx.doi.org/10.17582/journal.pjz/2017. 49.1.15.19.

Wang, X. G., Wang, Y. B., Ye, T., Lu, W. H. and Zhou, C. Y. 2018. Analyses of the growth characteristic of Portunus trituberculatus. Trans. Oceanol. Limnol., (2): 131-136.

Wu, Q., Wang, J., Chen, R. S., Huang, J. X., Zuo, T., Luan, Q. S. and Jin, X. S. 2016. Biological characteristics, temporalspatial distribution of Portunus trituberculatus and relationships between its density and impact factors in Laizhou Bay Bohai Sea, China. Chinese J. Appl.Ecol., 27(6): 1993-2001. DOI: 10.13287/j.1001-9332.201606.017.

Xu, W. J., Shi, H., Xu, H. X. and Small, H. 2007. Preliminary study on the Hematodinium infection in cultured Portunus trituberculatus. Acta Hydrobiol. Sin., 31(5): 637-642.

Yu, C. G., Song, H. T. and Yao, G. Z. 2004. Assessment of the crab stock biomass in the continental shelf water of the East China Sea. J. Fish. China, 28(1): 41-46. 
Yu, C. G., Song, H. T., Yao, G. Z. and Shen, X. L. 2003. Study on rational study or rational utilisation of crab resources in the inshore water of Zhejiang. Mar.Fish., 25(3): 136-141.
Yuan, W., Jin, X. S. and Shan, X. J. 2016. Population biology and relationship with environmental factors of swimming crab in the Changjiang river estuary and adjacent water. Fish. Sci., 35(2): 105-110.

Date of Receipt $\quad$ : 29.06.2018

Date of Acceptance : 30.11 .2018 